\title{
Improving adherence and outcomes in diabetic patients
}

\author{
This article was published in the following Dove Press journal: \\ Patient Preference and Adherence \\ 15 February 2017 \\ Number of times this article has been viewed
}

\section{Renu Joshi \\ Disha Joshi \\ Pramil Cheriyath}

Department of Endocrinology, Pinnacle Health Hospitals, Harrisburg, PA, USA
Correspondence: Renu Joshi

Department of Endocrinology, Pinnacle Health Hospitals, II I S. Front Street,

Harrisburg, PA I7I0I, USA

Tel + I $7|779| 2540$

Fax +I 717 79| 2549

Email rjoshi@pinnaclehealth.org
Objective: Nonadherence in diabetes is a problem leading to wasted resources and preventable deaths each year. Remedies for diminishing nonadherence are many but marginally effective, and outcomes remain suboptimal.

Aim: The aim of this study was to test a new iOS "app", PatientPartner. Derived from complexity theory, this novel technology has been extensively used in other fields; this is the first trial in a patient population.

Methods: Physicians referred patients who were "severely non-adherent" with HbA1c levels $>8$. After consent and random assignment $(n=107)$, subjects in the intervention group were immersed in the 12-min PatientPartner game, which assesses and trains subjects on parameters of thinking that are critical for good decision making in health care: information management, stress coping, and health strategies. The control group did not play PatientPartner. All subjects were called each week for 3 weeks and self-reported on their medication adherence, diet, and exercise. Baseline and 3-month post-intervention HbA1c levels were recorded for the intervention group.

Results: Although the control group showed no difference on any measures at 3 weeks, the intervention group reported significant mean percentage improvements on all measures: medication adherence (57\%, standard deviation [SD] 18\%-96\%, SD 9), diet (50\%, SD 33\%-75\%, SD 28), and exercise (29\%, SD 31\%-43\%, SD 33). At 3 months, the mean HbA1c levels in the intervention group were significantly lower (9.6) than baseline (10.7).

Conclusion: Many programs to improve adherence have been proved to be expensive and marginally effective. Therefore, improvements from the single use of a 12-min-long "app" are noteworthy. This is the first ever randomized, controlled trial to demonstrate that an "app" can impact the gold standard biological marker, HbA1c, in diabetes.

Keywords: diabetes, adherence, iOS app PatientPartner, HbA1c improvement

\section{Introduction}

Nonadherence to all treatments is a major problem in the US, where it is estimated to cost $\$ 300$ billion in wasted resources ${ }^{1}$ and leads to 125,000 unnecessary deaths ${ }^{2}$ each year. There is a similar and urgent problem among patients with diabetes, which is growing in prevalence and is the seventh leading cause of death. ${ }^{3}$ Patients with diabetes have lower than average adherence, ${ }^{1}$ and poor adherence leads to premature and significant morbidity (blindness, renal failure, congestive heart failure, and amputations). The cost of nonadherence in diabetes alone is in billions annually. ${ }^{4,5}$ In the largest study to date, Jha et $\mathrm{al}^{5}$ studied 135,600 patients with diabetes and defined adherence as taking their medications $80 \%$ of the time. They found that only $60 \%$ were adherent, a figure consistent with other studies. They found that nonadherent patients were $15 \%$ more likely to be hospitalized and use the emergency room. They calculated 
that improved adherence to diabetes medication could avert 699,000 emergency department visits and 341,000 hospitalizations annually, for a saving of $\$ 4.7$ billion. They also found that $25 \%$ of previously adherent patients became nonadherent over the following year. Preventing this loss of adherence would lead to another $\$ 3.6$ billion in savings, for a combined potential savings of $\$ 8.3$ billion each year. Recognizing this, many strategies and interventions have been used to increase adherence in patients with diabetes, including telemedicine, ${ }^{6}$ automated reminders, ${ }^{7}$ regimen simplification, ${ }^{8}$ regimen tailoring, ${ }^{9}$ electronic monitoring, ${ }^{10}$ motivational interviewing, ${ }^{11}$ diabetes education, ${ }^{12}$ and stratified patient-centered care. ${ }^{13}$

Clearly, there are many reasons for nonadherence, and there have been many interventions that have targeted each element. However, despite several of these approaches showing effectiveness, in general, glycemic control and overall outcomes remain unsatisfactory. ${ }^{14}$ Therefore, a novel approach has been studied, which is generic and aims to change the way patients think - and, more importantly, the decisions they make - about their health care. The technology behind this iOS "app" called PatientPartner is based on science-wide complexity theory, ${ }^{15}$ which has been distilled into an extensively validated, computerized, interactive, immersive experience called Strategic Management Simulation (SMS). The SMS system assesses parameters of thinking (the "how" of thinking that is independent of what one knows) and decision making, which have been shown over the past half century to predict real-world functioning in many fields. ${ }^{16-18}$ SMS assessments have also been able to detect subtle, high-level changes in thinking due to the effects of alcohol, antihistamines, beta blockers, ace inhibitors, tranquilizers, and more. ${ }^{19}$

SMS has been used in the health care field to assess, recruit, and improve the thinking and decision making of medical students, residents, and nursing students. ${ }^{20}$ Given this track record, it was hypothesized that SMS could be used to improve the thinking and decision making of patients, thereby improving adherence and outcomes. This is the first application of SMS in a patient population.

\section{Methods}

This study received approval from the institutional review board at Pinnacle Health, Harrisburg, PA and all subjects provided written consent. Because the intervention was with an iOS-based “app”, PatientPartner (PatientPartner is a product of CyberDoctor LLC), which is neither a drug nor a medical device, it did not need to be registered as a clinical trial.
A total of 107 subjects, age range from 17 to 71 years $(46 \%$ male and 54\% female), who attended a teaching hospital endocrinology clinic, were referred to the study based on two criteria: their physician judged them to be "severely non-adherent" despite efforts to engage them, and they had elevated glycosylated hemoglobin $(\mathrm{HbA} 1 \mathrm{c})>8$.

Subjects were randomly assigned to the intervention or control groups on a 2:1 ratio as they arrived in the clinic.

\section{Intervention group}

At the initial visit, patients in the intervention group played a game "PatientPartner" on an iPad. This 12-min game was played once, and it consisted of an engaging scenario of an easy-to-relate-to person with multiple real-world pressures (job and family) with "good excuses" for their obvious nonadherent health care behavior. Next, the subject immerses herself into this story and deals with these real-world pressures to reflect their typical behavior in their real life. Overall, the game is designed to help patients understand their choices and reach optimal decision points (Figure 1).

Subjects then work on a series of brief training vignettes to help them gain mastery over three parameters that are considered to be critical for good decision making in health care: information management, stress coping, and health strategies.

\section{Control group}

At the baseline visit, subjects in the control group agreed to 3 weekly self-reports via telephone; they did not engage with PatientPartner.

\section{Follow-up}

At the end of each week for 3 weeks, subjects in both the groups self-rated their adherence to medications, diet, and

\begin{tabular}{|l|l|}
\hline 1 "Meet the Patient" & $\begin{array}{l}\text { Patient reads a brief story of a non-compliant } \\
\text { character. }\end{array}$ \\
\hline 2 "Walk a Mile..." & $\begin{array}{l}\text { Patient makes choices on behalf of the character } \\
\text { during a complicated day. }\end{array}$ \\
\hline 3 “...In Their Shoes" & Patient witnesses the outcome of these choices. \\
\hline 4 "All About You" & $\begin{array}{l}\text { Patient re-reads brief story and this time makes } \\
\text { choices on their own behalf. }\end{array}$ \\
\hline 5 "Moment of \\
Reflection" & $\begin{array}{l}\text { Patient realizes similarity between the } \\
\text { non-compliant character and themselves. }\end{array}$ \\
\hline 6 "Growth" & $\begin{array}{l}\text { Patient receives feedback on thinking metrics and } \\
\text { can now practice in shorter modules. }\end{array}$ \\
\hline
\end{tabular}

Figure I The PatientPartner process. 
exercise. This was done over the telephone, and questions were strictly scripted to focus only on these adherence questions: "In the past week, how many days did you take your medicines/follow your diet/exercise?"

Three months after baseline, the HbAlc (done as per usual care in this clinic) was recorded for the intervention group. A decrease in HbA1c 3 months from baseline in this nonadherent group was the primary outcome of this study.

\section{Results}

A total of 107 participants were enrolled in the study and randomly assigned to two groups (intervention and control) in a 2:1 ratio. Of the 107 participants, 97 subjects completed the study with a total of 66 in the intervention group and 31 in the control group. An overall multivariate analysis of variance across data points indicated that quality of performance following intervention with PatientPartner exceeded performance in the absence of this intervention $(P<0.001)$. Following this, analysis of variance comparisons were made between the PatientPartner group and controls on percent adherence at baseline and at 3 weeks on self-reports on medication, diet, and exercise. Obtained means and standard deviations as well as $F$ values and significance levels for each of these variables are reported in Table 1. The control group was not different on any of these three measures. The PatientPartner group made significant improvements in adherence on all the three measures (Figure 2).

Three months after the PatientPartner intervention, HbA1c had dropped from 10.71 at baseline to 9.62 ( $F$ ratio 4.14, $P<0.05)$ as shown in Figure 3.

\section{Discussion}

Diabetes is a rapidly growing condition throughout the world. Although good treatments are available to control it, this goal is defeated by nonadherence to all three pillars of treatment: medication, diet, and exercise. Diabetes medication

Table I Mean changes in intervention and control group on medication, diet, and exercise at 3 weeks

\begin{tabular}{|c|c|c|c|c|c|}
\hline Variables & $\mathbf{N}$ & $\begin{array}{l}\text { Base } \\
\text { mean (\%) }\end{array}$ & $\begin{array}{l}\text { Final } \\
\text { mean (\%) }\end{array}$ & $F$ ratio & $P$-value \\
\hline \multicolumn{6}{|c|}{ Intervention group 66} \\
\hline Medication & & 57 (SD I8) & 96 (SD 9) & 386 & 0.001 \\
\hline Diet & & 50 (SD 33) & 75 (SD 28) & 28.7 & 0.001 \\
\hline Exercise & & 29 (SD 3I) & 43 (SD 33) & 7.6 & 0.007 \\
\hline Control group & 31 & & & & \\
\hline Medication & & 58 (SD 20) & 68 (SD 45) & I.I & 0.30 \\
\hline Diet & & 35 (SD 29) & 48 (SD 36) & 0.74 & 0.39 \\
\hline Exercise & & 32 (SD 23) & 31 (SD 24) & 0.92 & 0.34 \\
\hline
\end{tabular}

Abbreviation: SD, standard deviation.

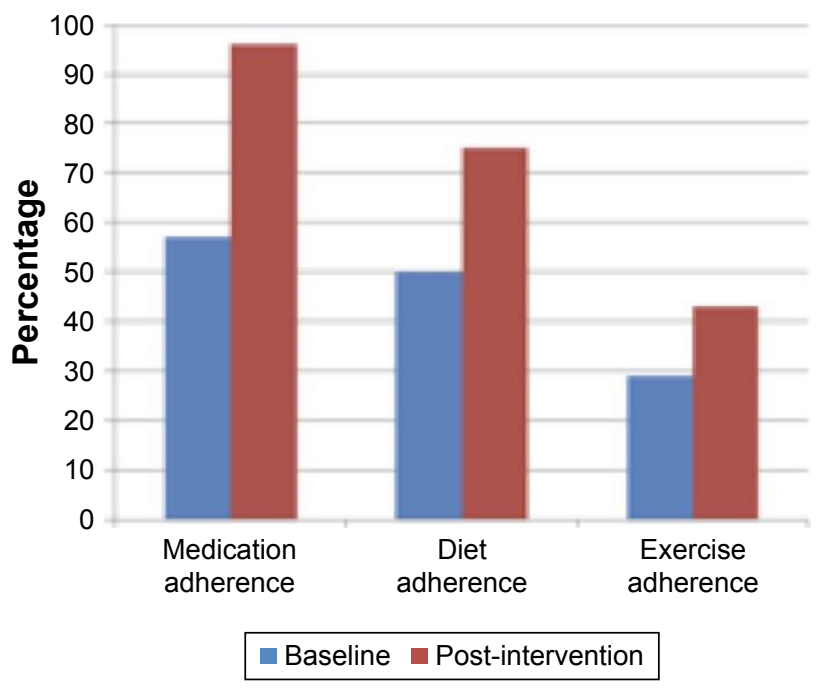

Figure 2 Mean changes in intervention group on medication, diet, and exercise at 3 weeks.

adherence rates are low compared to even other chronic diseases. ${ }^{1}$ As borne out again by our results, adherence to medication is low, diet is difficult, and exercise is poor. The current study shows that apps such as PatientPartner could play a key role in improving the outcomes as reflected in improved adherence behaviors.

There is a strong evidence that treating type 2 diabetes can decrease morbidity and mortality and provides the basis for renewed attempts in addressing this effectively. ${ }^{23}$ Many creative approaches, for example, disease management and telemedicine, have been shown to be helpful but require ongoing, expensive interventions and are often abandoned. Clearly, new and innovative interventions that are brief require little expertise to administer and are capable of being easily administered to a large number of patients are the need of the hour. In this context, it is impressive that a brief (12 min), one-time noninvasive intervention with PatientPartner can change outcome behaviors and lead to patients

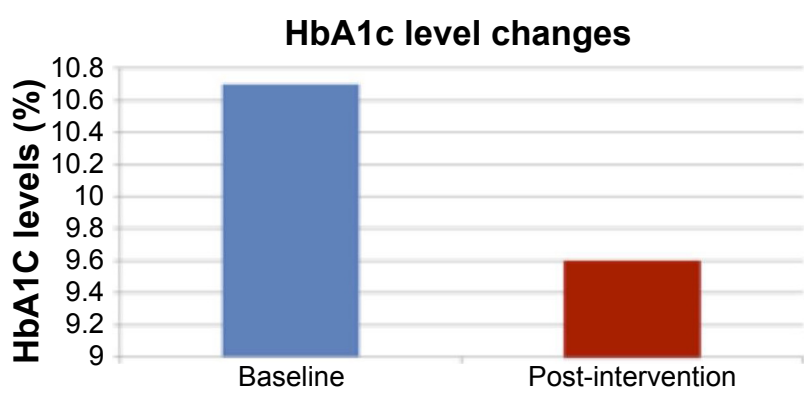

Figure 3 Mean change in $\mathrm{HbAlc}$ levels in intervention group between baseline and 3 months.

Abbreviation: $\mathrm{HbAlc}$, glycosylated hemoglobin. 
taking their medication more regularly (from $\sim 4$ days a week to almost every day), eating a healthier diet (from 3.5 days a week to over 5), and exercising regularly (clearly the most difficult, it went up from 2 days a week to 3). Although this is statistically significant and clinically meaningful, it is short term (just 3 weeks) and is based on self-reports. To remedy this, the primary end point chosen was $\mathrm{HbA1c}$, the objective, biological gold standard for blood glucose that is an average of levels over 3 months. With just one brief intervention, there was a significant and clinically meaningful drop in HbA1c from 10.7 to 9.6. Although 9.6 is still high, a decrease of 1.1 in 3 months in a very nonadherent group is noteworthy.

Today, $>200,000$ medical apps are available. Numerous apps can monitor and reward, for example, through "gaming" principles, the progress of a person's diabetes. However, this is the first app that has been proven in a clinical trial to be effective in improving an objective biological marker of diabetes, HbA1c. More importantly, this is a general app that affects the way people think and make decisions (including about their health) but is not in any way geared specifically to diabetes. Therefore, this app has the potential to improve the care and outcome not just in diabetes but in any medical condition.

This is a pilot study with shortcomings. The sample needs to be larger. Given limited resources, our strategy was to recruit chronically poorly controlled patients to see whether we could make an impact in the most difficult population. We do not know the utility of this app in the general population of people with diabetes although it looks promising. Diabetes is a chronic disease, and a 3-month trial is short; we need to study it long term to evaluate for how long this one 12-min intervention can exert a positive influence. When would a booster session be needed?

The app was well tolerated by all ages, including the elderly. All subjects could complete the game, including the many subjects who were disadvantaged (less educated or from lower socioeconomic strata), as is typical of a public clinic.

Medical apps such as PatientPartner can be added to the many approaches that we currently use and have the potential to improve adherence and outcomes and decrease costs for the care of patients with chronic illness (including billions of dollars for diabetes alone). However, apps need to be clinically tested and proven effective before being adopted. There is only one app that is specific to cancer and that has been proven to be helpful. ${ }^{24}$ There is only one effective app, PatientPartner, which is nonspecific to any particular disease because it focuses on three general parameters of thinking and decision making: information management, stress coping, and health strategies. This pilot study shows that patients can be assessed and trained in a very short time. Teaching them skills to solve real-world relevant problems in innovative, sequential, and strategic ways can help improve adherence behaviors. This can therefore be effective in all diseases. More studies are needed to prove PatientPartner's effectiveness in other disease states.

Our review suggests that improved adherence among patients with diabetes (and all chronic diseases) should be a key goal for clinicians, the health care system, and policy makers. Given the less than optimal results from current approaches, new and innovative approaches need to be encouraged, clinically tested, and then implemented.

\section{Disclosure}

The authors report no conflicts of interest in this work.

\section{References}

1. DiMatteo MR. Variations in patients' adherence to medical recommendations: a quantitative review of 50 years of research. Med Care. 2004; 42:200-209.

2. Martin LR, Williams SL, Haskard KB, DiMatteo MR. The challenge of patient adherence. Ther Clin Risk Manag. 2005;1:189-199.

3. Centers for Disease Control and Prevention. National Diabetes Fact Sheet: National Estimates and General Information on Diabetes and Prediabetes in the United States, 2011. Atlanta, GA: U.S. Department of Health and Human Services, Centers for Disease Control and Prevention; 2011.

4. Dunbar-Jacob J, Mortimer-Stephens MK. Treatment adherence in chronic disease. J Clin Epidemiol. 2001;54(Supp1 1):S57-S60.

5. Jha AK, Aubert RE, Yao J, Teagarden JR, Epstein RS. Greater adherence to diabetes drugs is linked to less hospital use and could save nearly \$5 billion annually. Health Aff. 2012;8:1836-1846.

6. Trief P, Izquierdo R, Eimick J, et al. Adherence to diabetes self care for white, African-American and Hispanic American telemedicine participants: 5 year results from the IDEATel project. Ethn Health. 2013; 18(1):83-96.

7. Piette JD, Weinberger M, Kraemer FB, McPhee SJ. Impact of automated calls with nurse follow-up on diabetes treatment outcomes in a Department of Veterans Affairs Health Care System: a randomized controlled trial. Diabetes Care. 2001;24:202-208.

8. Saini SD, Schoenfeld P, Kaulback K, Dubinsky MC. Effect of medication dosing frequency on adherence in chronic diseases. Am J Manag Care. 2009; 15:e22-e33.

9. Bosworth HB, Granger BB, Mendys P, et al. Medication adherence: a call for action. Am Heart J. 2011;162:412-424.

10. Granger BB, Bosworth HB. Medication adherence: emerging use of technology. Curr Opin Cardiol. 2011;26:279-287.

11. Possidente CJ, Bucci KK, McClain WJ. Motivational interviewing: a tool to improve medication adherence? Am J Health Syst Pharm. 2005;62: 1311-1314.

12. Graumlich JF, Wang H, Madison A, et al. Effects of a patient-provider collaborative, medication-planning tool: a randomized controlled trial. J Diabetes Res. 2016; Epub 2016 Sep 6.

13. Slingerland AS, Herman WH, Redekop WK, et al. Stratified patient-centered care in type 2 diabetes: a cluster-randomized, controlled clinical trial of effectiveness and cost-effectiveness. Diabetes Care. 2013;36(10):3054-3061.

14. Pladevall M, Williams LK, Potts LA, Divine G, Xi H, Lafata JE. Clinical outcomes and adherence to medications measured by claims data in patients with diabetes. Diabetes Care. 2004;27:2800-2805. 
15. Streufert S, Satish U. Complexity theory: predictions based on the confluence of science-wide and behavioral theories. J Appl Soc Psychol. 1997:27:2096-2116.

16. Satish $\mathrm{U}$, Mendell $\mathrm{M}$, Shekhar $\mathrm{K}$, et al. Is $\mathrm{CO}_{2}$ an indoor air pollutant? Direct effects of low-to-moderate $\mathrm{CO}_{2}$ concentrations on human decision-making performance. Environ Health Perspect. 2012; 120(12):1671-1677.

17. Satish U, Streufert S. Improving strategic performance on multiple dimensions: an analysis via complexity theory. In: Winning Strategies in a Deconstructing World. Wiley, Berlin: Strategic Management Society. 1999:42.

18. Streufert S, Satish U, Swezey RW. Effective assessment and training with quasi-experimental simulations. In: Handbook of the International Military Testing Association. Defense Publishing Service, Sydney, Australia: Defense Publishing Service; 1998:455-462.

19. Streufert S, Pogash R, Braig D, et al. Alcohol hangover and managerial effectiveness. Alcohol Clin Exp Res. 1995;19(5):1141-1146.
20. Satish U, Krishnamurthy S, Dewan M. The role of cognitive simulation in health care. In: Riley R, editor. A Manual of Simulation in Healthcare. 2nd ed. London: Oxford; 2015.

21. Gonzalez JS, Schneider H, Wexler D, et al. Validity of medication adherence self-reports in adults with type 2 diabetes. Diabetes Care. 2013; $36: 831-837$

22. Aikens JE, Piette JD. Longitudinal association between medication adherence and glycemic control in type 2 diabetes. Diabet Med. 2013; 30:338-344.

23. The Diabetes Control and Complications Trial Research Group. The effect of intensive treatment of diabetes on the development and progression of long-term complications in insulin-dependent diabetes mellitus. N Engl J Med. 1993;329:977-986.

24. Kato PM, Cole SW, Bradlyn AS, Pollock BH. A video game improves behavioral outcomes in adolescents and young adults with cancer: a randomized trial. Pediatrics. 2008;122:e305.

\section{Publish your work in this journal}

Patient Preference and Adherence is an international, peer-reviewed, open access journal that focuses on the growing importance of patient preference and adherence throughout the therapeutic continuum. Patient satisfaction, acceptability, quality of life, compliance, persistence and their role in developing new therapeutic modalities and compounds to optimize clinical outcomes for existing disease states are major areas of interest for the journal. This journal has been accepted for indexing on PubMed Central. The manuscript management system is completely online and includes a very quick and fair peer-review system, which is all easy to use. Visit http://www. dovepress.com/testimonials.php to read real quotes from published authors.

Submit your manuscript here: http://www.dovepress.com/patient-preference-and-adherence-journal 